\title{
A Qualitative Study of Sleep and Mood in Postpartum Women
}

\author{
Leslie M. Swanson ${ }^{1, *}$, J. Todd Arnedt ${ }^{1}$, Roseanne Armitage ${ }^{1}$, Jennifer Adams ${ }^{2}$ and Heather Flynn ${ }^{3}$ \\ ${ }^{I}$ Department of Psychiatry, University of Michigan, Ann Arbor, MI, USA \\ ${ }^{2}$ Northeastern University, Boston, MA, USA \\ ${ }^{3}$ Florida State University, Tallenassee, FL, USA
}

\begin{abstract}
Sleep disruption and insomnia are common features of the postpartum period and may predispose women to develop affective illness. The aim of this study was to explore sleep and mood during the postpartum period in women at risk forpostpartum depression. Thirteen postpartum women participated in focus groups designed to elicit information about sources of sleep disruption, how sleep changes impacted their mood, and their preferences for insomnia treatments. Transcripts from the focus groups were analyzed using a grounded theory framework. Major themes included: mental arousal and breastfeeding are major sources of sleep disruption; women are ambivalent about accessing nighttime support; it is difficult for women to prioritize sleep; poor sleep leads to mood dysregulation; and women prefer nonpharmacological treatments for insomnia. Understanding sleep from the perspective of postpartum women can help inform treatments for insomnia in this population.
\end{abstract}

Keywords: Sleep, insomnia, depression, postpartum.

\section{INTRODUCTION}

The perinatal period represents a challenging time for childbearing women to consistently obtain quality sleep [1]. Changes in sleep patterns relative to preconception begin in the first trimester, as women experience a reduction in slowwave sleep that persists until delivery [2]. Sleep time decreases across pregnancy as sleep fragmentation increases $[3,4]$. Total sleep time sharply declines in the first month postpartum [4], and this corresponds to the period of highest risk for development or recurrence of affective illness [5]. Although sleep loss and fragmentation are normal during the postpartum period, persistent difficulty in falling asleep or returning to sleep when the infant is sleeping may signal insomnia. An emerging body of literature shows that poor sleep quality and symptoms of insomnia are linked to depressive symptoms in new mothers [3, 6-8].

In non-postpartum populations with depression, insomnia symptoms hinder treatment response [9-11] and commonly persist after remission from depression has been achieved [12-14]. Poor sleep quality increases risk for relapse in postpartum women who have histories of depression [15]. Therefore, interventions to improve sleep may also improve depressive symptoms for women with postpartum depression. Given the lack of safety data on medications traditionally used to treat sleep disturbances in adults, such as benzodiazepine receptor agonists, treatment options for lactating postpartum women are relatively limited.

*Address correspondence to this author at the 4250 Plymouth Rd, Ann Arbor, MI 48109, USA; Tel: 734-764-1234; Fax: 734-764-1229;

E-mail: LMSwan@med.umich.edu
The impetus for the present study was to understand sleep during the postpartum period in women who were at risk for postpartum depression and had significant mood symptoms. The focus included the major sources of sleep disruption, how sleep disruption is associated with mood changes, and their preferences for treatment. We chose to use a qualitative methodology for data collection because qualitative data provide a rich and deep source of information. The interaction that occurs between participants during group interviews facilitates expression of opinions and attitudes that might not emerge from individual interviews; therefore, we elected to use focus groups [16].

\section{METHODS}

\section{Participants}

The research protocol was approved by the University of Michigan Institutional Review Board.Written informed consent was obtained from all participants. We recruited women for the study from the University of Michigan Department of Psychiatry outpatient clinics and from communities in southeastern Michigan. Women were eligible for the study if they were within 12 months postpartum, had Edinburgh Postnatal Depression Scale [17] scores $\geq 12$, Insomnia Severity Index [18] scores $\geq 8$, and reported spending $\geq 60$ minutes awake during the night trying to fall asleep or return to sleep at least 3 nights per week when their infant was sleeping or not otherwise a factor in their sleep. Participants were excluded from the study if they had symptoms of other sleep disorders, including obstructive sleep apnea, restless legs syndrome, or periodic limb movement disorders. Other exclusionary criteria included history of, or suspicion for, any of the 
Table 1. Demographic Characteristics of the Sample

\begin{tabular}{|c|c|c|c|}
\hline & n (\%) or $M \pm S D$ & & n (\%) \\
\hline Age, years & $32 \pm 4$ & Education & \\
\hline Number of Children & $2 \pm 1$ & $\leq 12$ years & $1(8)$ \\
\hline Months Postpartum & $4 \pm 3$ & Some college & $4(31)$ \\
\hline Race & & College graduate & $8(62)$ \\
\hline Caucasian & $8(62)$ & \multirow{3}{*}{$\begin{array}{c}\text { Marital Status } \\
\text { Married or partnered } \\
\text { Divorced } \\
\text { Single }\end{array}$} & \multirow{3}{*}{$\begin{array}{c}11(85) \\
1(8) \\
1(8)\end{array}$} \\
\hline African American & $4(31)$ & & \\
\hline Asian & $1(8)$ & & \\
\hline
\end{tabular}

Note. $\mathrm{M}=$ mean; $\mathrm{SD}=$ standard deviation.

following diagnoses: bipolar disorder, substance dependence, posttraumatic stress disorder, or psychosis.

\section{Data Collection}

All of the focus groups were led by one of the investigators (LS). Four focus groups were conducted. Groups ranged in size from 2 to 5 women. Interview questions were developed using consensus among the investigators about both general topic areas and specific questions. The interview was open-ended and designed to elicit information about experiences with sleep, such as changes in sleep, sources of sleep disruption, effects of sleep disruption on daytime functioning and mood; nighttime care for the infant; and sleep treatment preferences. The focus groups lasted approximately 90 to 120 minutes. The interviews were audiotaped.

\section{Data Analysis}

Audiotapes of the interviews were transcribed, coded, and analyzed using $\mathrm{N}$ Vivo software [19]. We used an iterative coding and analysis process informed by grounded theory to structure the data analysis. Grounded theory uses an inductive approach in which hypotheses emerge from, and are generated by, the data [20]. In the first stage, three of the investigators (TA, HF, LS) independently reviewed two transcripts and identified themes, which were used to create codes. Transcripts were then independently coded by each of the investigators. The investigators met as a group to identify common themes, refine and revise codes, delineate subthemes, and classify relationships between themes and subthemes. A final coding structure was achieved when no additional themes or codes emerged from the data. Two previously uncoded transcripts were then coded by all three investigators using the final coding system; agreement was $80 \%$ among the coders for these two transcripts. As the last coding step, one of the investigators (LS) recoded all of the transcripts with the finalized coding system.

\section{RESULTS}

Thirteen women participated in the study. Their demographic information is presented in Table 1. Mean Edinburgh Postnatal Depression Scale score was 14.92 (SD = 5.19), and mean Insomnia Severity Index score was 15.04
$(\mathrm{SD}=4.83)$, indicating moderately severe depression and insomnia.

The following major themes emerged from the data: mental arousal and breastfeeding or pumping breast milk are major sources of sleep disruption; ambivalence about accessing support for nighttime infant care; prioritizing sleep is difficult; poor sleep leads to significant mood dysregulation; and women prefer non-pharmacological treatment options for insomnia. Each of these themes will be discussed in detail below, with accompanying quotations to illustrate main points.

\section{Cognitive Arousal and Feeding Interrupt Sleep}

Participants described several different sources of sleep disruption, including bed partners, infants, other children, and pets. The most commonly identified reason that women had difficulty sleeping was cognitive arousal. They described being so occupied and busy during the day that the quiet of the sleep period provided them the opportunity to think or plan: "Most of the thinking goes on when I'm going to bed. Because that is just the only time that I don't have [the baby] to focus on, or phone calls to be making, and getting ready for work...that's it". For some participants, their mood state led to mental arousal at bedtime: "I'll think about events during the day when I'm trying to fall asleep. So if I'm having a very depressed day and focused on all of the negative stuff that happened, then it's like I'm replaying that stuff when I'm going to bed. Or I'm worrying about what my part was in all of that or I'm worrying about how did someone interpret what I did during the day. It's almost like it's a 'beat-up on me' time". Another participant expressed "I just honestly don't know how to shut down the mind", a sentiment shared by many of the women. One participant described a solution that worked for her to manage mental arousal: "I also keep a piece of paper or a notepad next to my book [on the nightstand] to write down that list of different things to do the next day. Otherwise, I'll sit there and think I have to do all of these things tomorrow: a, b, c, d, e, f, g and then I'm like, 'what were they again?'”.

Concern and anticipation of when their infant would wake were also a source of arousal that interrupted sleep: "I kind of know when the baby is going to wake up. Sometimes it's hard to sleep because you know you're just going to be disrupted again". Another participant said: "I lie in bed and I 
know she's going to be awake another half an hour later or twenty. And I just don't end up sleeping. I do that multiple times at night and never sleep".

Beyond cognitive arousal, the physical demands of breastfeeding and pumping breast milk were described as major sources of sleep disruption. Pumping milk was described as much more time consuming than breast feeding:" It's just... pumping is like doing it twice because most of the time you end up having to give them the bottle. Sure, other people can, but it's so... Or you have to warm a bottle. It's a lot of work, a lot of extra work. And it's for your baby, but [pause] everybody makes their own decisions". Guilt about switching to formula was a major theme for those women who decided to stop feeding breast milk: "So I pumped for the first month and a half...it was horrible and it really had such a poor impact on sleep. And I went back and forth feeling awful about quitting and thinking 'What if my son gets cancer?' or something like that". Once breastfeeding was discontinued, participants described improvement in their sleep: "If you're breastfeeding, you have to get up and pump anyways because your breasts are really full and they hurt. So even if someone's letting you sleep through the night, you can't sleep through the night because you're engorged. And it did get better once I stopped breastfeeding because at least I had someone to help and feed the child by giving him formula". One participant, however, identified breastfeeding as a positive time: "Yeah, it's a time where she's calm and...it's actually great. That's my opportunity to sit down and rest".

\section{Poor Sleep Leads to Significant Mood Dysregulation}

All of the women clearly attributed increased depression, irritability, and anxiety to lack of sleep. One woman who was unable to sleep for an extended period of time immediately following the birth of her baby said: "And then I look back...once I was allowed to sleep again, two days later I looked back on the exact same events and I couldn't remember why I started bawling and crying and acting like it was the end of the world. It was just the lack of sleep". Sleep also protected women from mood problems: "Just being so overwhelmed with everything. If you have the sleep you tend to be able to deal with that sort of thing a little bit more". Irritability was consistently identified as a major consequence of sleep loss. For some women, the irritability was so excessive it interfered with their ability to parent their children, and it impacted relations with their partner: "I'm definitely more irritable. I don't really want to do much. With my oldest, if she wants to play a board game-no, I just don't feel like it. It's causing a lot of problems with my relationship because I deal with the baby all day, and I can't take it out on my baby, not that I'd want to, but you stay composed. But then when there's another adult there at times, that's where your release is, it's on him". Another woman said: "[I'm] short tempered. I'm sure I'm not as much fun for my two and a half year old". Irritability also leads to social isolation: "You definitely get cranky and irritable and [it's] hard to deal with others. I just want to be left alone. I'm not answering any phone calls. You just want to be in your own zone."
Even Though Sleep Loss Has Significant Consequences, Women Are Ambivalent About Nighttime Support

The women who participated in this study clearly identified sleep loss and disruption as a contributor to mood problems. Many of them recognized that assistance in caring for the child would likely improve their sleep: "If I had more consistent help and I wouldn't have to figure everything out for myself and I would be able to unwind, then I could probably sleep better". However, even though most of the women knew that having help with care giving would improve their sleep and their mood, many of them described ambivalence and guilt about asking for help taking care of the infant at night. A woman who had enlisted her husband's assistance in sharing nighttime care for their baby said:" But then I'd just feel bad, I'd be like, but he's sleeping and he needs his sleep so I'll just do the change as well. So I do the change as well and then I also walk her and rock her back to sleep. And then I put her back in the bassinette. And then I just lie there because I know she's going to get up and those are the times I'd be up until 7:00 - when I was trying to save him the trouble of getting up. You know, it was supposed to be more even, but each time I'd be like, 'Why should I wake him up just for a five minute change? Why should I wake him up just to walk around for 10 minutes? I can do that too'",.

A desire to protect their partner from sleep loss emerged as a strong motivating force to shoulder the burden of nighttime childcare alone. A woman whose husband worked full-time while she stayed at home to care for the children said: "He's the one who has to go to work all day so he has to function. So I'm the one who gets up with them [children]". Guilt was another factor:"I also have feelings of guilt, that someone is helping me. You know, I should be able to do all of this by myself. But then when you are with them by yourself, you're going crazy and you can't wait to get help. It's a lot of mixed emotions".

Women who enlisted the support of their partners in caring for the baby during the night noted benefit from the arrangement: "But I was so affected by not sleeping, that my husband finally let me sleep through the night. So if my son is fussy and he needs his pacifier then my husband will get up and do it just so I can sleep. Because he saw that he is much better at getting up in the middle of the night and still being able to function during the day. Where it was really affecting my mood and I was having trouble even making it through the day". One woman who said that she often found herself lying awake waiting for her baby to wake up to feed noted: "And if it's a night that my husband has committed to taking care of the baby, then I feel a lot better when I get sleep". Still, other women said they would have trouble sleeping while their partner was caring for the infant if they had been awakened by the baby's cries: "Even if he gave her a bottle or something, I lay there and I'll be awake". Sometimes women were not confident in the care their husbands were providing, which also led to sleep disruption: "If I hear her crying too long and he's with her, I'll come out to figure out what's going on; why is she crying so much and what is he doing about it?" 


\section{Prioritizing Sleep is Difficult}

Prioritizing sleep over self-care activities or personal interests was difficult for most of the women. Many of the participants described decision points where they had to choose between sleeping or spending time engaged in a task they would not otherwise have time to complete: "It's like I'm reaching for time for myself, down time. I really should just sleep...even when I'm falling asleep at the computer, I'll go on the computer or turn on the TV. It's like you just want to have some time for yourself, but that's where I think I mess myself up". Even when they had planned to nap, other things would intervene: "And even during the day when the baby sleeps, like today, I was thinking as soon as the baby goes to sleep I'm going to take a little cat nap before I take a shower. And I didn't, of course. [The baby] fell asleep and I had lunch and then I got on the computer to check my email, which is the worst thing". A woman who described struggling with lack of time to even take a shower said: "You have to ask yourself, 'Do I want a nap or do I want a shower?" Another mother who would wake early in the morning to feed her infant said she preferred to stay awake to accomplish household chores instead of returning to sleep: "I'll get up at 4 AM, and it's like I could have so much housework done by $6 \mathrm{AM}$, I could vacuum, take the garbage out, the diaper bag cleaned. So I get caught up in that".

\section{Preference for Nonpharmacological Sleep Treatment Strategies}

Participants were asked about their experiences with medications for sleep and their thoughts on using medications to treat their insomnia. The majority of women who had tried a hypnotic medication described feeling groggy when they used it: "The next day I would wake up and I was so groggy". Even if it helped them to sleep, they still did not want to use medication for sleep: "I just didn't feel good even though it did help me go to sleep. I don't want to rely on sleeping pills". One woman who had used a hypnotic medication before she had children, noted that the medication helped until she had children: "Medication did work prior to the babies coming", but after she gave birth she was concerned about grogginess from the medication: "I'd like to take the pills again to help me sleep, but it seems to me that I'll be too tired to get up because I'm already tired and trying to get up at the right time". Many women were concerned about how it would affect their ability to care for the infant at night: "And I would take it [sleep medication] and it would make me really tired and I would go right to sleep as soon as [baby] was down. But I found that when I had to get up in the middle of the night with him, I'd feel dizzy", or: "I just feel like it's dangerous when you're carrying a baby around feeling like that and stuff. So that made me not want to take it as much, but [it] did help me relax". A woman who had never used medication said: "I'm just afraid of being so out of it that something happens and I wouldn't be able to wake up for the baby and the other kids". Women who were breastfeeding were worried about transmitting the drug to the infant: "I just don't want to take the risk [of medication passing into breast milk]. Until I'm done breastfeeding I'm not willing to take any medication".

\section{DISCUSSION}

We found that sleep is challenging for women with young infants who are also experiencing depressive symptoms. The reasons for this are multifaceted and complex. Several clear themes emerged from the data that help to shed light and clarify relationships between caregiving for an infant and sleep. Understanding these relationships is important to help guide and inform development of treatments for insomnia in this population.

Proposed models of chronic insomnia posit that engaging in non-sleep related activities in bed (e.g., thinking, planning, watching TV) leads to conditioned arousal, whereby the bedroom environment becomes so strongly associated with wakefulness and arousal that it eventually elicits an arousal response automatically [21, 22]. The experiences of postpartum women with insomnia certainly support this hypothesis. In some ways the unique demands of caring for an infant may predispose women to develop conditioned arousal to the bedroom environment. Bedtime is often the only time women with young infants have to plan or process the events of the day, and physically being in bed while they are thinking may minimize the likelihood that their planning or thinking will be interrupted. Further, women often spend long periods of time breastfeeding, pumping breast milk, or soothing their infant in bed while they are awake. These findings suggest that behavioral techniques such as stimulus control therapy [23] (instructions designed to associate the bed and bedroom with rapid sleep onset) could be an effective component of any insomnia treatment for postpartum women. However, the standard procedures may require creative modification and flexibility, especially if women are breastfeeding or pumping.

Many of the women we interviewed struggled with breastfeeding and described a strongly negative impact of breastfeeding on their sleep. However, they were also reluctant to switch to formula because of feelings of guilt and worry over whether the switch would affect their child's health. Sending a balanced message to women about the benefits and possible drawbacks of breastfeeding, especially for those at risk for postpartum depression, may make this difficult choice easier.

A cognitive schema emerged from what the women told us about their expectations for themselves as mothers. They perceived their role in the family as the sole provider of all or almost all of the care for the baby, and other children, even if they were also working outside of the home. They expected that they should be able to meet the intensive demands of caring for an infant alone and if they needed assistance, it meant they were flawed in some way, which led to guilty feelings when they were unable to fulfill this expectation. This schema seems pervasive and has implications for women's sleep. Concern for their partner's wellbeing led them to protect them from nighttime sleep loss by not asking for support or assistance. Incorporating cognitive restructuring techniques $[24,25]$ focused on changing these schemas to be more adaptive, as well as normalizing the need for support from others, may in turn lead to sleep improvements. 
Perhaps as a result of the expectations that women hold regarding their duties as mothers, they do not have time to engage in tasks that fulfill the need for pleasurable activities or even basic self-care, such as showering or devoting sufficient time to sleep. When faced with a choice between sleep and doing something else, sleeping is typically less of a priority. This is remarkable considering the adverse consequences of sleep loss described by the same women. Although engaging in pleasurable activities may help improve mood, sacrificing sleep to do so may ultimately hinder recovery from depression. This highlights the need for care providers to explicitly discuss with postpartum women the importance of sleep and to help women generate strategies that enable them to have time for themselves while retaining a reasonable amount of time to devote to sleep.

The emerging body of literature on sleep during the postpartum period and mood is consistent with the experiences described by the focus group participants $[3,6$, 8]. Data from non-postpartum samples show that insomnia and sleep disruption increase risk for the development of mood disorders [26]. However, there are very few prospective or longitudinal studies in childbearing women; a recent prospective study showed that poor sleep quality was a predictor for relapse to major depressive disorder in the postpartum period for women with histories of depression [15]. Our results suggest that exploration of sleep loss as a causal mechanism for mood dysregulation in postpartum women will be an important focus for future research.

There was great consensus among the participants regarding use of medications for sleep. Almost all of the women, including those who had tried medications for sleep, expressed that they are uncomfortable using medications for sleep. The majority of them cited concerns about the medication impairing nighttime care giving, or fear of the medication passing through their breast milk. Women who had tried medication treatments reported dissatisfaction with how the medication made them feel the next day. These findings speak to the need for nonpharmacological treatments tailored to the postpartum population.

There are a few limitations of the present study that warrant discussion. First, the women who participated in this study may have been less depressed or experienced different symptoms of depression than women who did not volunteer for the study. Second, the study may have attracted participants who had particular thoughts about sleep, or perceptions of treatments for insomnia (such as medications). Finally, our sample was small and drawn exclusively from southeastern Michigan, which may limit generalizability to women in other regions of the United States.

Despite these limitations, this study represents a step towards increasing knowledge and awareness about sleep during the postpartum period. Childbearing women face major barriers to obtaining consistently good quality sleep. Our findings substantiate the significant need for nonpharmacological treatment options for insomnia in women who have young infants. Such treatments should incorporate elements addressing the themes that emerged from this study. The themes raised by this study also suggest areas for future study with larger perinatal samples, including longitudinal research focused on causal relationships between sleep and depression; how breastfeeding impacts sleep; and how relationships and social support affect sleep.

\section{CONFLICT OF INTEREST}

The authors confirm that this article content has no conflicts of interest.

\section{ACKNOWLEDGEMENTS}

This research was supported by the University of Michigan Rachel Upjohn Clinical Scholars Award (LS).

\section{REFERENCES}

[1] Lee K. Alterations in sleep during pregnancy and postpartum: a review of 30 years of research. Sleep Med Rev 1998; 2: 231-42.

[2] Lee KA, Zaffke ME, McEnany G. Parity and sleep patterns during and after pregnancy. Obstet Gynecol 2000; 95: 14-8.

[3] Bei B, Milgrom J, Ericksen J, Trinder J. Subjective perception of sleep, but not its objective quality, is associated with immediate postpartum mood disturbances in healthy women. Sleep 2010;33: 531-8.

[4] Montgomery-Downs H, Insana S, Clegg-Kraynok M, Mancini L. Normative longitudinal maternal sleep: The first 4 postpartum months. Am J Obstet Gynecol 2010; 203: 461-5.

[5] Gavin NI, Gaynes BN, Lohr KN, et al. Perinatal depression: A systematic review of prevalence and incidence. Obstet Gynecol 2005; 106: 1071-83.

[6] Goyal D, Gay CL, Lee KA. Patterns of sleep disruption and depressive symptoms in new mothers. J Perinat Neonatal Nurs 2007; 21: 123-9.

[7] Huang CM, Carter PA, Guo JL. A comparison of sleep and daytime sleepiness in depressed and non-depressed mothers during the early postpartum period. J Nurs Res 2004; 12: 287-96.

[8] Dørheim S, Bondevik G, Eberhard-Gran M, Bjorvatn B. Sleep and depression in postpartum women: A population-based study. Sleep 2009; 32: 847-55.

[9] Dew MA, Reynolds CF, 3rd, Houck PR, et al. Temporal profiles of the course of depression during treatment. Predictors of pathways toward recovery in the elderly. Arch Gen Psychiatry 1997; 54: 1016-24.

[10] Thase ME, Buysse DJ, Frank E, et al. Which depressed patients will respond to interpersonal psychotherapy? The role of abnormal EEG sleep profiles. Am J Psychiatry 1997; 154: 502-9.

[11] Buysse DJ, Tu XM, Cherry CR, et al. Pretreatment REM sleep and subjective sleep quality distinguish depressed psychotherapy remitters and nonremitters. Biol Psychiatry 1999; 45: 205-13.

[12] Carney CE, Segal ZV, Edinger JD, Krystal AD. A comparison of rates of residual insomnia symptoms following pharmacotherapy or cognitive-behavioral therapy for major depressive disorder. J Clin Psychiatry 2007; 68: 254-60.

[13] Nierenberg AA, Husain MM, Trivedi MH, et al. Residual symptoms after remission of major depressive disorder with citalopram and risk of relapse: A STAR*D report. Psychol Med 2010; 40: 41-50.

[14] Taylor D, Walters H, Vittengl J, Krebaum S, Jarrett R. Which depressive symptoms remain after response to cognitive therapy of depression and predict relapse and recurrence? J Affect Disord 2010; 123: 181-7.

[15] Okun ML, Luther J, Prather AA, et al. Changes in sleep quality, but not hormones predict time to postpartum depression recurrence. J Affect Disord 2011; 130: 378-84.

[16] Kitzinger J. Qualitative research: Introducing focus groups. BMJ 1995; 311: 299-302.

[17] Cox J, Holden J, Sagovsky R. Detection of postnatal depression. Development of the 10-item Edinburgh Postnatal Depression Scale. Br J Psychiatry 1987; 150: 782-6.

[18] Bastien CH, Vallires A, Morin CM. Validation of the Insomnia Severity Index as an outcome measure for insomnia research. Sleep Med 2001; 2: 297-307.

[19] NVivo qualitative data analysis software. $8^{\text {th }}$ ed. QSR International Pty Ltd. 2009.

[20] Glaser BG, Strauss AL. The discovery of grounded theory; strategies for qualitative research. Chicago, I.L: Aldine Pub, 1967. 
[21] Perlis ML, Giles DE, Mendelson WB, Bootzin RR, Wyatt JK. Psychophysiological insomnia: the behavioural model and a neurocognitive perspective. J Sleep Res 1997; 6: 179-88.

[22] Spielman AJ, Caruso LS, Glovinsky PB. A behavioral perspective on insomnia treatment. Psychiatr Clin North Am 1987; 10: 541-53.

[23] Bootzin RR, Nicassio PM. Behavioral treatments for insomnia. In: Hersen M, Eissler R, Miller P, Eds. Progress in behavioral modification. New York, Academic Press 1978; pp. 1-45.
[24] Beck AT. Depression: clinical, experimental, and theoretical aspects. New York: Hoeber, 1967.

[25] Ellis A. Overcoming destructive beliefs, feelings, and behaviors: New directions for rational emotive behavior therapy. Amherst, N.Y: Prometheus Books, 2001.

[26] Breslau N, Roth T, Rosenthal L, Andreski P. Sleep disturbance and psychiatric disorders: a longitudinal epidemiological study of young adults. Biol Psychiatry 1996; 39: 411-8.

Received: November 23, 2011

Revised: September 06, 2012

Accepted: January 26, 2013

(C) Swanson et al.; Licensee Bentham Open.

This is an open access article licensed under the terms of the Creative Commons Attribution Non-Commercial License (http://creativecommons.org/licenses/by$\mathrm{nc} / 3.0 /$ ), which permits unrestricted, non-commercial use, distribution and reproduction in any medium, provided the work is properly cited. 